\title{
Development of Hot-Rolled Sheet Steel with Significant Increase in Tensile Strength Induced by Strain Age Hardening*
}

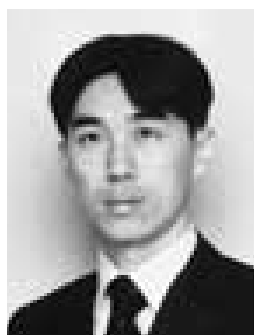

Shinjiro Kaneko Senior Researcher, Technical Res. Labs. Sheet Lab.,

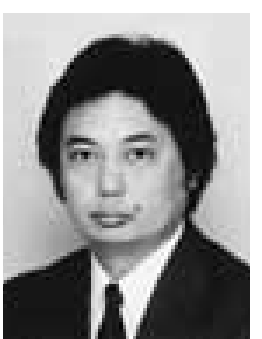

Jiro Hiramoto Senior Researcher, Forming Technology Center, Technical Res. Labs.

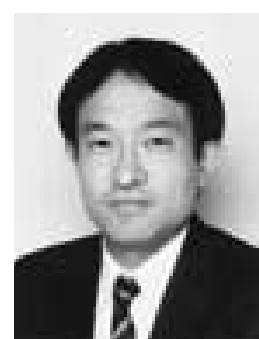

Takashi Ishikawa Staff Manager, Sheet \& Strip Sec., Products Service \& Development Dept., Chiba Works

\section{Introduction}

With stricter crashworthiness regulations and the start of public disclosure of crash test results in recent years, auto makers are developing auto body structures with excellent crashworthiness, but safety measures such as increasing the thickness of body structural parts and adding reinforcement, etc. tend to increase auto body weight. ${ }^{1)}$ On the other hand, stricter regulations have also been applied to $\mathrm{CO}_{2}$ emissions from the viewpoint of environmental problems, and consequently, auto makers have been striving for the reduction of body weight in order to improve fuel consumption. ${ }^{2-4)}$ In response to these trends, auto makers are studying the use of high strength sheet steels in auto body structural parts, as it is possible to increase the strength of body members and to reduce weight by using thinner gauge materials. ${ }^{5-8)}$ However, because formability generally deteriorates as the strength of sheet steel is increased, ${ }^{9-11)}$ the development of sheets which provide both strength and formability has been strongly desired.

Kawasaki Steel developed a hot-rolled sheet steel which exhibits low strength and excellent formability during forming, but shows a large increase in strength after paint baking, and also possesses a satisfactory anti-

* Originally published in Kawasaki Steel Giho, 35(2003)1, 28-32
Synopsis:

A new type of bake-hardenable high strength hotrolled sheet steel was developed, which shows remarkable increase in tensile strength as well as yield strength after strain age hardening without addition of special elements. The new sheet steel possesses excellent crashworthiness and high fatigue strength, and also shows good formability almost equal to that of conventional high strength sheet steels. This unique combination of properties makes it possible to reduce the weight of the car body by using thinner gauge material when the new sheet steel is applied to crash-resistant parts and underbody parts.

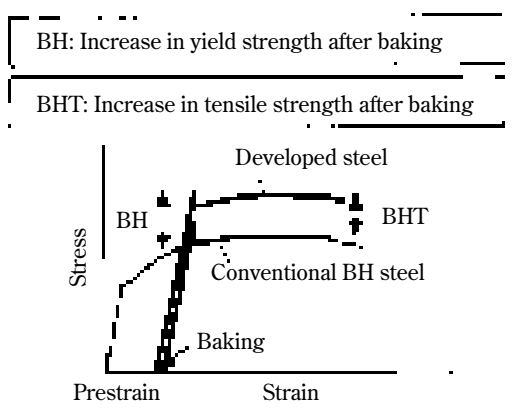

Fig. 1 Stress-strain relationship of developed steel after strain aging

aging property at room temperature. This was achieved by appropriate adjustment of the solute $\mathrm{N}$ content of the steel combined with refinement of the grain structure by high accuracy cooling control in hot rolling process. ${ }^{12-16)}$

Figure 1 is a schematic illustration of the stress-strain curve of the developed steel after strain age hardening in comparison with a conventional bake-hardening $(\mathrm{BH})$ sheet steel. ${ }^{17-19)}$ With the conventional $\mathrm{BH}$ sheet, yield strength is increased by paint baking, but deformation stress in the plastic deformation region is on the same level as the non-baked sheet. For this reason, the applications of conventional $\mathrm{BH}$ material have been limited 
to the exposed panels of the auto body, where dent resistance is necessary. In contrast, the developed sheet shows a remarkable increase in yield strength, exceeding that of the conventional $\mathrm{BH}$ sheet, and at the same time, also shows improved tensile strength. These important advantages make it possible to apply the developed sheet to auto body structural members where crashworthiness and/or fatigue properties are required.

This report describes the various properties of the developed sheet steel and presents the results of a study of application of the new sheet to the auto body.

\section{Manufacturing Principle and Mechanism of Increased Tensile Strength in Developed Sheet}

A high strain age hardening capacity is realized in the developed sheet steel by using the element $\mathrm{N}$, which has higher solubility in the hot-rolling temperature region than C. Figure 2 shows a schematic diagram of the hot rolling cooling process used in producing the developed sheet. In order to secure solute $\mathrm{N}$ in the sheet, precipitation of AIN is suppressed by controlling the cooling conditions after hot rolling. At the same time, deterioration of mechanical properties due to room temperature aging is suppressed by refinement of the grain size. This is accomplished by rapid cooling after hot rolling, which causes the solute $\mathrm{N}$ in the steel to segregate to a stable position at the grain boundary. This process makes it possible to satisfy both of the mutually contradictory requirements of a high strain age hardening capacity and an anti-aging property at room temperature.

To clarify the mechanism by which paint baking enhances the tensile strength of the developed steel, the authors carried out the following study.

Photo 1 shows the influence of paint baking on the

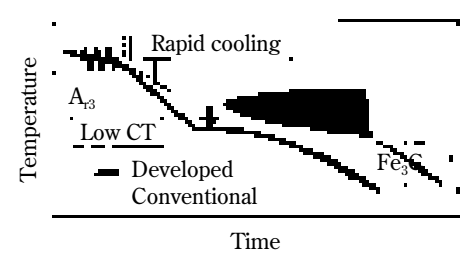

Fig. 2 Schematic diagram of hot-rolling process

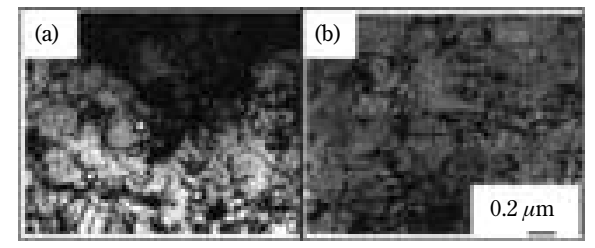

(a) $10 \%$ prestrain $\rightarrow 170^{\circ} \mathrm{C} \times 20 \mathrm{~min} \rightarrow 4.5 \%$ strain

(b) $14.5 \%$ strain

Photo 1 Dislocation networks of developed steel induced by tensile strain with or without baking treatment dislocation substructure of the developed steel after the tensile test. Photo 1(a) shows the results of TEM observation of a sample when paint baking was performed after applying 10\% prestrain, and additional strain of $4.5 \%$ was applied after baking. Photo $1(\mathrm{~b})$ shows the case of deformation up to $14.5 \%$ without paint baking. In the material which was given paint baking treatment, a dislocation loop and tangling of dislocations can be clearly observed, as indicated by the arrows in the figure, and it can be understood that the dislocation density has increased in comparison with the non-paint baked material. This is attributed to the fact that the dislocations which were introduced by prestrain became firmly locked during paint baking, and the plastic deformation which was applied after paint baking encouraged multiplication of dislocations. The external force required for multiplication of dislocations increases as the dislocations become more strongly and densely locked at the dislocation source. Moreover, the external force required for movement of a dislocation in a dislocations after multiplication also increases as the dislocation density becomes larger. Thus, the increased tensile strength observed after paint baking is considered to be a result of the higher stress generated by these dislocation multiplication during plastic deformation. This study confirmed the presence of fine precipitates on dislocations in the stage when aging treatment was performed after prestraining. In the tangled dislocation region, it is assumed that these precipitates serve as sites for the locking/multiplication of dislocations.

Because the X-ray diffraction half-width becomes greater as the dislocation density increases, the phenomenon described above was verified by measuring the changes in the X-ray diffraction half-width with and without paint baking. The X-ray diffraction half-width was evaluated using the half-width increase ratio $(\Delta d / d)$ in comparison with non-paint baked material, based on measurements of the (222) peak half-width.

Figure 3 shows the influence of paint baking on the X-ray diffraction half-width. Paint baking increased the half-width of the X-ray diffraction peak, corroborating the assumption that the dislocation density is increased by paint baking.

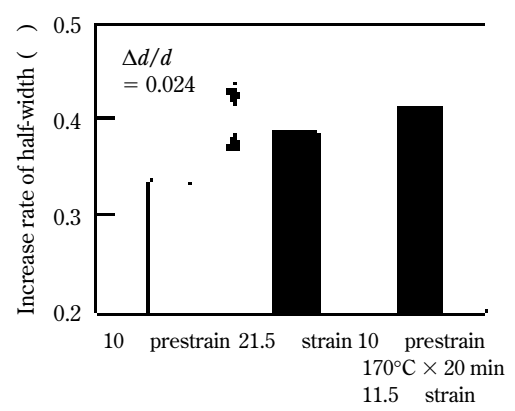

Fig. 3 Effect of baking treatment on (222) peak half-width of developed steel 


\section{Features of Developed Sheet Steel}

As a basic functional evaluation for application of the developed sheet steel to the structural parts of automobiles, the authors investigated the strain age hardening characteristics, formability, dynamic (high speed) deformation behavior, fatigue properties, and anti-aging property at room temperature of the developed steel.

\subsection{Sample Steel}

TS440 MPa sheets of the developed steel were manufactured on a commercial production line as samples for the respective tests. Table 1 shows an example of mechanical properties.

\subsection{Strain Age Hardening Characteristics}

For the tensile test, JIS 5 test pieces were taken from the developed sheet (thickness: $1.4 \mathrm{~mm}$ ) parallel to the rolling direction. After prestraining in the range of $0 \sim 15 \%$ by uniaxial tensioning, heat treatment under conditions equivalent to paint baking was performed by immersion in an oil bath at $170^{\circ} \mathrm{C} \times 20 \mathrm{~min}$, and the tensile test was then repeated. Strain aging characteristics were investigated by measuring the amounts of $\mathrm{BH}$ and increase in BHT at this time. The amounts of BH and BHT are defined as shown in Fig. 1. BH was obtained by subtracting the stress when prestrain was applied from the yield stress when the tensile test was repeated after treatment simulating paint baking. BHT was obtained by subtracting the tensile stress of the mother sheet from the tensile stress in the tensile test after simulated paint baking.

Figure 4 shows the influence of prestrain on $\mathrm{BH}$ and

Table 1 Typical mechanical property of developed steel $(t=1.4 \mathrm{~mm})$

\begin{tabular}{lcccc}
\hline \hline $\begin{array}{c}\text { YS } \\
(\mathrm{MPa})\end{array}$ & $\begin{array}{c}\mathrm{TS} \\
(\mathrm{MPa})\end{array}$ & $\begin{array}{c}\mathrm{El} \\
(\%)\end{array}$ & $\begin{array}{c}\mathrm{BH} * \\
(\mathrm{MPa})\end{array}$ & $\begin{array}{c}\text { BHT** } \\
(\mathrm{MPa})\end{array}$ \\
\hline 370 & 478 & 34 & 95 & 57 \\
\hline$*$ Increase in yeild strength after strain aging $(2 \%$ & prestrain $\rightarrow$ \\
$170^{\circ} \mathrm{C} \times 20$ min) \\
**Increase in tensile strength after strain aging $(10 \%$ prestrain $\rightarrow$ \\
$170^{\circ} \mathrm{C} \times 20$ min)
\end{tabular}

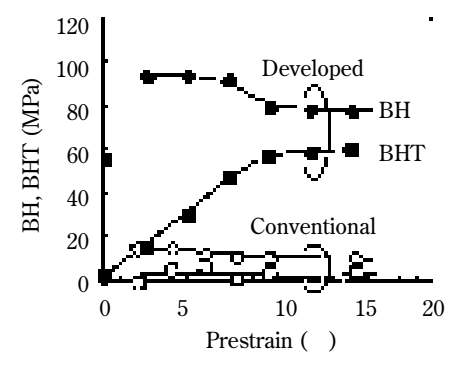

Fig. 4 Effect of prestrain on BH and BHT of developed steel
BHT in comparison with a conventional sheet steel. In the conventional sheet, $\mathrm{BH}$ tended to decrease as the amount of prestrain increased, and showed a maximum value of $20 \mathrm{MPa}$. In contrast, the $\mathrm{BH}$ of the developed sheet showed a value of approximately $100 \mathrm{MPa}$ with $2 \%$ prestrain. As with the conventional sheet, $\mathrm{BH}$ tended to decrease as prestrain increased, but the developed sheet showed a high value of approximately $80 \mathrm{MPa}$, even with prestrain of $10 \%$ or more.

With the conventional sheet, BHT was negligibly small regardless of the amount of prestrain, but in contrast, the BHT of the developed sheet increased with prestrain and showed a value of approximately $60 \mathrm{MPa}$ when $10 \%$ prestrain was applied. Moreover, there was little change in BHT when the prestrain was increased above $10 \%$.

As described above, by applying strain of $10 \%$ or more to the developed sheet steel, it is possible to secure a large and stable increase in strength after treatment simulating paint baking.

\subsection{Formability}

In order to evaluate formability, a forming test of the developed steel (thickness: $1.6 \mathrm{~mm}$ ) was performed at various strain ratios to obtain the forming limit points, and forming limit diagrams (FLD) were then prepared. A scribed circle with a diameter of $6 \mathrm{~mm}$ was transcribed onto the blank material, and strain measurements were performed by the rupture area measurement method.

Figure 5 shows the FLD of the developed sheet in comparison with that of a conventional TS440 MPa sheet. Even in a deformation route comprising all of the balanced biaxial stretch region-plane strain region-uniaxial tension region, the forming limit of the developed steel was almost equal to that of the conventional steel, indicating that the formability of the new material is in no way inferior. Specifically, it can be suggested that the developed sheet has formability almost equal to that of conventional sheets of the same strength level, while also possessing a high strain age hardening capacity.

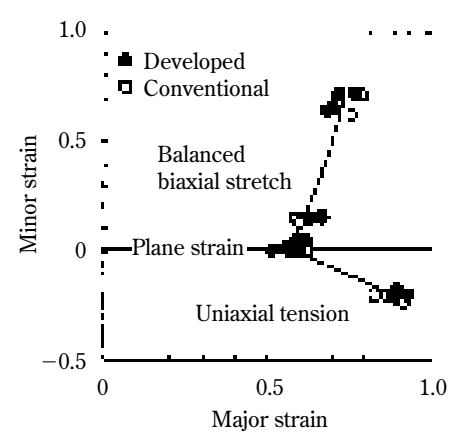

Fig. 5 Forming limit diagram of developed steel compared with that of conventional steel (Thickness: $1.6 \mathrm{~mm}$ ) 


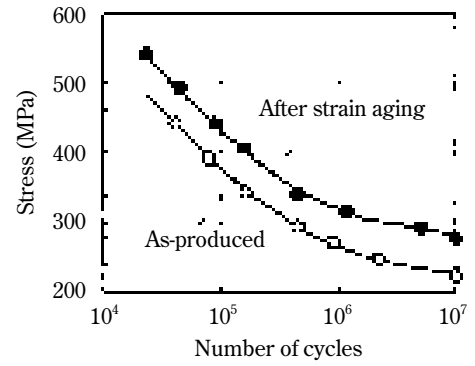

Fig. 6 Influence of strain aging on fatigue strength of developed steel

Table 2 Fatigue property of developed steel

\begin{tabular}{c|cc}
\hline \hline & As received & After baking* \\
\hline Fatigue limit & 221 & $276(\mathrm{MPa})$ \\
FL/TS & 0.44 & 0.50 \\
\hline \multirow{2}{*}{ (10\% Pre-strain $\rightarrow 170^{\circ} \mathrm{C} \times 20 \mathrm{~min}$}
\end{tabular}

\subsection{Fatigue Characteristics}

A plane bending fatigue test of the developed steel (thickness: $1.6 \mathrm{~mm}$ ) was performed using the as-produced sheet and specimens which were given $10 \%$ prestrain, followed by treatment simulating paint baking (immersion in oil bath at $170^{\circ} \mathrm{C} \times 20 \mathrm{~min}$ ), to obtain $S$ $N$ curves and fatigue limits.

Figure 6 shows a comparison of the $S-N$ curves of the developed steel with and without strain-aging treatment. Fatigue strength increased by approximately $60 \mathrm{MPa}$ in both the low cycle and high cycle regions when $10 \%$ prestrain was applied, followed by treatment simulating paint baking. Table 2 summarizes the fatigue characteristics of the developed sheet. The fatigue limit was $221 \mathrm{MPa}$ in the as-produced sheet condition, but increased to $276 \mathrm{MPa}$ as a result of strain-aging treatment. At the same time, the fatigue ratio also improved to 0.50 with strain aging, in contrast to 0.44 in the asproduced sheet condition. Thus, it can be understood the fatigue characteristics are improved remarkably by strain age hardening.

The results described above show that the developed sheet steel can be effectively applied to automotive chassis components and other parts where fatigue characteristics are an important requirement.

\subsection{Dynamic Deformation Behavior}

Test pieces with a gauge width of $2.5 \mathrm{~mm}$ and gauge length of $3.8 \mathrm{~mm}$ were taken from the developed sheet for a high strain rate tensile test using a split-Hopkinson pressure bar apparatus. ${ }^{20)}$ The strain rate was approximately $2000 / \mathrm{s}$. The test was performed using the as-produced sheet and specimens which were given $10 \%$ prestrain, followed by treatment simulating paint baking (immersion in oil bath at $170^{\circ} \mathrm{C} \times 20 \mathrm{~min}$ ). Absorbed energy was calculated from the stress-strain relationship

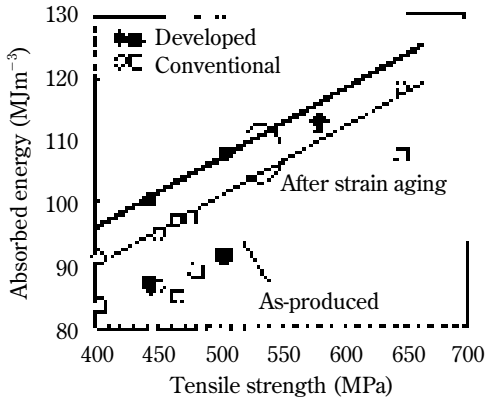

Fig. 7 Absorbed energy at high strain rate tensile testing of developed steel compared with conventional steel

by integration of stress values up to a strain of $15 \%$.

Figure 7 shows the absorbed energy of the developed sheet in the high strain rate tensile test and the correlation with the TS of the as-produced sheet, in comparison with a conventional sheet steel. The absorbed energy of the as-produced sheet increased as TS increased, and the developed sheet showed an identical correlation with the conventional sheet. When specimens were given $10 \%$ prestrain, followed by treatment simulating paint baking, both the conventional sheet and the developed sheet showed a positive correlation between absorbed energy and the TS of the as-produced sheet, as when simulated paint baking was not performed. However, the absolute value of the developed sheet was higher than that of the conventional sheet. With the conventional sheet, absorbed energy increased by approximately $10 \mathrm{MJm}^{-3}$ due to work hardening, whereas, with the developed sheet, the increase was approximately $16 \mathrm{MJm}^{-3}$. This can be attributed to the contribution of increased strength resulting from strain age hardening, in addition to work hardening. When converted to the increase in the TS of the as-produced sheet, the contribution of strain age hardening to absorbed energy is equivalent to approximately $60 \mathrm{MPa}$. Thus, the increase in strength (BHT) measured in the ordinary tensile test is also apparent in the same effect in the high strain rate tensile test.

These results show that the developed sheet steel can be applied effectively to anti-crash parts.

\subsection{Anti-aging at Room Temperature}

After temper (skinpass) rolling of the developed sheet at an elongation of $1.5 \%$, the material was left at room temperature, and tensile tests were performed at intervals of approximately 3 months over a period of one year to investigate secular changes in mechanical properties.

Figure 8 shows the changes in the mechanical properties of the developed sheet when aged at room temperature in comparison with a conventional sheet steel. Even when aged for one year, the developed sheet showed virtually no change in TS. YS increased by 


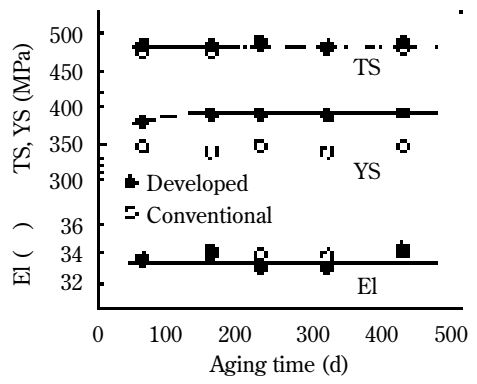

Fig. 8 Changing in mechanical properties during room temperature aging $(t=1.6 \mathrm{~mm})$

approximately $30 \mathrm{MPa}$, and the reduction in El showed a very slight change, at a maximum of approximately $2 \%$.

It was previously known that deterioration of mechanical properties as a result of aging at room temperature is a problem in strain age hardening sheets. However, with the developed sheet steel, it was possible to realize a large strain age hardening effect, while simultaneously suppressing deterioration of properties due to room temperature aging, by controlling the chemical composition and grain size of the steel.

\section{Functional Analysis by Finite Element Method (FEM)}

In order to verify the crashworthiness of the developed sheet in case of application to automotive structural parts, a finite element method (FEM) crash analysis was performed assuming a hat-shaped square column. Figure 9 shows the configuration of the hat-shaped square column used in this analysis. The cross section was a hat-shaped square with sides of $60 \mathrm{~mm}$ each and a corner radius $R$ of $5 \mathrm{~mm}$. The length of the column was $300 \mathrm{~mm}$, and spot welding of the flange at a $30 \mathrm{~mm}$ pitch was assumed. The amount of strain and reduction in

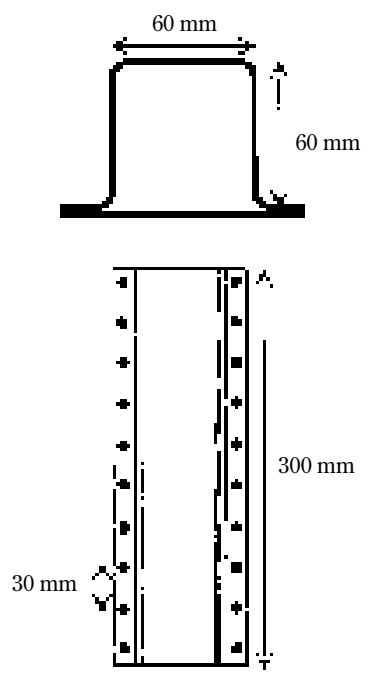

Fig. 9 Configuration of hat square column

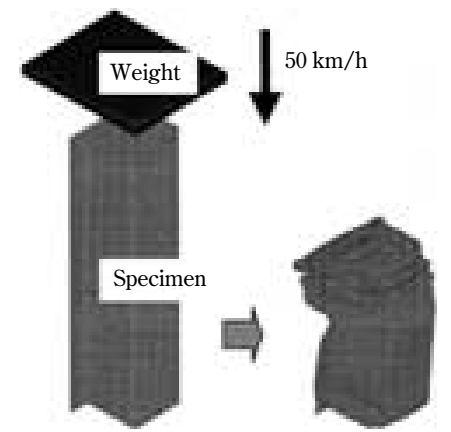

Fig. 10 Model of crash testing

Table 3 Mechanical properties of materials used in FEM analysis

\begin{tabular}{c|ccl}
\hline \hline Steel & YS (MPa) & TS (MPa) & \\
\hline A & 263 & 374 & Conventional \\
B & 332 & 465 & Conventional \\
C & 378 & 628 & Conventional \\
D & 387 & 500 & Developed \\
E & 287 & 400 & Developed (Assumed) \\
F & 487 & 600 & Developed (Assumed) \\
\hline
\end{tabular}

sheet thickness resulting from press forming were calculated by an FEM forming analysis. Forming strain in the corner $R$ of the hat-shaped square column was set at $9 \%$. Forming strain in the vertical wall parts was set at $15 \%$. The thickness reduction ratio in the corner parts and general parts was $0 \%$, while that in the vertical wall parts was set at 10\%. As shown in Figure 10, the crash analysis was performed in the axial compression mode by impacting a rigid weight weighing approximately $550 \mathrm{~kg}$ in the axial direction of the hat-shaped square column at a speed of $50 \mathrm{~km} / \mathrm{h}$.

Table 3 shows the properties of the materials used in the analysis. The materials were conventional sheet steels (Steels $\mathrm{A} \sim \mathrm{C}$ ) with varying strength levels between 370 590 MPa, and the developed steel (Steel D), with TS of $500 \mathrm{MPa}$. Sheet thicknesses of $1.4 \sim 1.6 \mathrm{~mm}$ were used. The data employed in preparing stress-strain curves for the analysis were data for a strain rate of $0.02 \mathrm{~s}^{-1}$, which were obtained with JIS 5 test pieces, and data for a strain rate of $2000 \mathrm{~s}^{-1}$, which was measured using the above mentioned split-Hopkinson pressure bar apparatus. In order to consider the amount of forming strain, stress-strain curves were prepared by performing a tensile test after heat treatment at $170^{\circ} \mathrm{C} \times 20 \mathrm{~min}$, following prestrain of $0 \sim 15 \%$. In addition to the actual developed steel (Steel D), which had a measured value of TS500 MPa, hypothetical stress-strain curves were prepared for the developed material assuming TS400 MPa and TS600 MPa (Steel E, F) by subtracting or adding $100 \mathrm{MPa}$ to the stress-strain curve of the actual steel, and were used in an equivalence quantification analysis. 


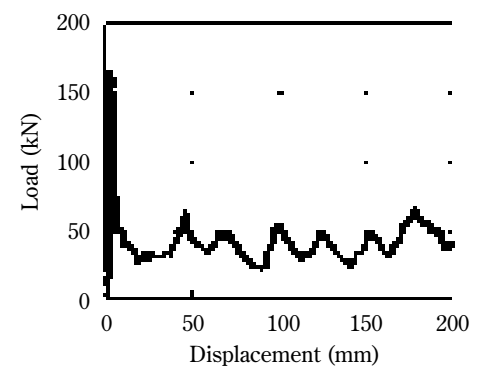

Fig. 11 Typical load-displacement curve of hat square column

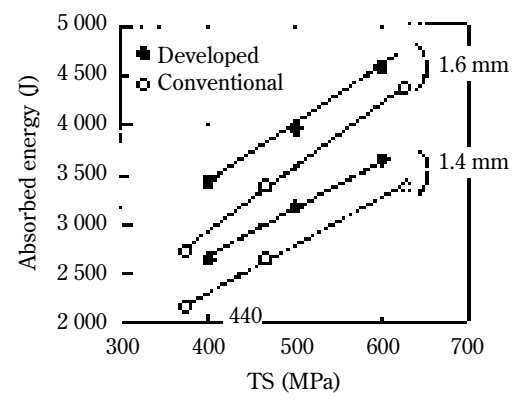

Fig. 12 Relation between absorbed energy and tensile strength

As shown in Fig. 10, the hat-shaped square column deformed from the top, in an accordion shape corresponding to the pitch of the spot welds, due to compression in the axial direction. Figure 11 shows a typical load-displacement curve. The load-displacement curve first shows a large load peak, which occurs simultaneously with impact. However, as deformation proceeds, the curve shows load oscillations corresponding to deformation at each of the pleats in the accordion bellows. Figure 12 shows the relation between absorbed energy at this time and the initial TS of the material. Absorbed energy was obtained by integrating the loaddisplacement curve up to a displacement of $60 \mathrm{~mm}$. With all the sheet thicknesses, the absorbed energy of the conventional sheet and developed sheet showed a positive correlation with the initial TS of the material. However, the absolute value of absorbed energy was higher in the developed sheet than in the conventional material. This was because strain age hardening contributed to an increase in the strength of the developed sheet, as was expected from the high strain rate tensile test. When converted to the amount of increase in the initial TS of the material, the contribution of strain age hardening was equivalent to approximately $60 \mathrm{MPa}$. Thus, as above, the effect of increased strength (BHT), as measured in the conventional tensile test, was also apparent in increased absorbed energy. Moreover, the contribution of strain age hardening can be converted to a sheet thickness of approximately $0.1 \mathrm{~mm}$. In weight terms, this is equivalent to a weight reduction of $7 \%$.
From the results presented above, it is clear that application of the developed sheet allows the auto maker to enhance crashworthiness without increasing auto body weight, or conversely, to reduce body weight while maintaining the same crashworthiness.

\section{Conclusions}

A new high strength hot-rolled sheet steel (BHT sheet) was developed by applying strain age hardening. An investigation of various material properties and a functional analysis (crash analysis) of the developed steel were performed with the following results.

(1) The mechanism of increased tensile strength in the developed sheet steel is considered to be as follows: Dislocations are introduced in the sheet during prestraining and are then firmly locked by the paint baking process. Plastic deformation after paint baking promotes multiplication of dislocations from these locked dislocations, and this increases the external force which is required for dislocations to move through dislocations.

(2) When heat treatment simulating the paint baking process was performed after imparting prestrain of $10 \%$ or more to the developed sheet, the material showed an increase of $80 \mathrm{MPa}$ or more in yield strength and an increase of approximately $60 \mathrm{MPa}$ in tensile strength.

(3) The effect of increased tensile strength in the developed sheet improves fatigue characteristics and also increases absorbed energy in dynamic (high speed) deformation.

(4) The developed sheet possesses formability equal to that of conventional sheet steels of the same TS level.

(5) When the developed sheet was aged at room temperature for one year, the increase in YS was approximately $30 \mathrm{MPa}$, and the decrease in $\mathrm{El}$ due to room temperature aging deterioration was extremely small, at a maximum of approximately $2 \%$.

(6) The contribution of strain age hardening to the crashworthiness of the developed sheet was equivalent to a TS of applroximately $60 \mathrm{MPa}$, which corresponds to a sheet thickness reduction of approximately $0.1 \mathrm{~mm}$. Thus, the developed steel can contribute to weight reduction by enabling the auto maker to reduce material thickness, or to securing the formability of hard-to-form parts (by reducing the strength level).

The developed sheet steel is expected to make a large contribution to safety and to the solution of environmental problems, which are now required in automobiles.

\section{References}

1) Y. Kuriyama, M. Takahashi, and M. Ohashi: J. of JSAE, 55(2001), 51

2) M. Ohashi: Tetsu-to-Hagané, 68(1982), 1136

3) N. Okubo: Sosei-to-Kakou, 21(1980)229, 92

4) T. Hamanaka: Sosei-to-Kakou, 33(1992)375, 337 
5) A. Yasuda, O. Furukimi, and Y. Seino: Kawasaki Steel Giho, 32(2000)1, 1-6

6) M. Shibata: 180th Symposium of Technol. Plast., (1998), 9

7) K. Miura, S. Takagi, T. Kato, O. Matsuda, and S. Tanimura: Materia Japan, 35(1996)5, 570

8) K. Miura, S. Takagi, T. Hira, and O. Furukimi: SAE Technical Paper, No. 980952

9) H. Hayashi: J. of JSAE, 49(1995), 5

10) E. Izuka, T. Hira, and O. Furukimi: CAMP-ISIJ, 12(1999), 1222

11) E. Izuka, J. Hiramoto, T. Hira, and O. Furukimi: Proc. of JSAE, (1999)81-99, 21

12) S. Kaneko, J. Hiramoto, S. Matsuoka, and K. Sakata: Proc. of JSAE, (2001)11-01, 1

13) J. Hiramoto, S. Kaneko, T. Hira, K. Sakata, and H. Abe: Proc. of JSAE, (2001)11-01, 5

14) S. Kaneko, J. Hiramoto, S. Matsuoka, and K. Sakata: CAMPISIJ, 14(2001), 1386

15) S. Kaneko, A. Tosaka, K. Sakata, F. Kosumi, and I. Hishinuma: Materia Japan, 41(2002), 48

16) S. Kaneko, J. Hiramoto, S. Matsuoka, A. Tosaka, and K. Sakata: SAE Technical Paper, No. 2002-01-0040

17) S. Satoh, T. Irie, and O. Hashimoto: Tetsu-to-Hagané, 68 (1981)9, 236

18) M. Kurosawa, S. Satoh, T. Obara, and K. Tsunoyama: Kawasaki Steel Giho, 19(1987)2, 119

19) S. Satoh, S. Okada, T. Kato, O. Hashimoto, T. Hanazawa, and H. Tsunekawa: Kawasaki Steel Giho, 23(1991)4, 293

20) K. Miura, S. Takagi, O. Furukimi, and S. Tanimura: J. of JSMS, 47(1998)10, 1053 